\title{
Acquired right ventricular outflow tract obstruction
}

\author{
David H. Drachler, M.D. \\ Park W. Willis, III, M.D. \\ Ann Arbor, Mich.
}

$\mathbf{I}^{\mathrm{t}}$

is not unusual for complicated aneurysms of the ascending aorta to affect left ventricular function. Processes causing or associated with an aneurysm may narrow the coronary artery ostia and produce myocardial ischemia or infarction; the aneurysm may distort the aortic valve ring and produce aortic insufficiency with subsequent left ventricular hypertrophy, dilatation, and failure. However, an unusual manner in which an aortic aneurysm can lead to heart failure is by right ventricular outflow tract obstruction. Here, the clinical picture often resembles that of pulmonic stenosis.

This report describes such a complication of an aortic aneurysm and focuses attention on the variety of mechanisms by which acquired right ventricular outflow tract obstruction may be produced

\section{Case report}

A. D. (UMMC 084202), a 57-year-old Caucasian housewife, was admitted Sept. 14, 1964, because of chronic back and chest pain. She had sustained fractures of the left clavicle and the left lower extremity in an automobile accident 12 years earlier and since then had noticed an intermittent left subscapular ache which did not limit activity. In 1960 , she was refused employment because of a chest $\mathrm{x}$-ray abnormality. Five months prior to admission the pain increased in frequency and severity. It radiated to an area beneath the left breast and varied with position and respiration. It did not resemble

typical angina pectoris. She also experienced dyspnea on mild excrtion and threc episodes of transicnt lightheadedness. She had not had syncope or hemoptysis. There was no history of rheumatic fever, vencrcal disease, or heart murmur.

The blood pressure was $130 / 80 \mathrm{~mm}$. $\mathrm{Hg}$ and the pulse rate 86 with a regular thythm. The trachea was in the midline and the neck veins were not distended in the supine position. The carotid artery pulses were normal. The lungs were clear. The heart was not enlarged. A prominent left parasternal lift was present, but there were no thrills. The second sound split physiologically. A Grade $3 / 6$ harsh systolic ejection murmur was present over the entire precordium but was loudest in the third intercostal space at the left sternal border. It radiated to the neck, left axilla, and the lung bases. There were no diastolic murmurs. The peripheral pulses were normal and equal bilaterally. Cyanosis, clubbing, and ederna were absent.

The hematocrit was 37 per cent and the white cell count was 4,700 with a normal differential. The serology was negative. A fasting blood sugar was 81 $\mathrm{mg}$. per cent, the urea nitrogen $18 \mathrm{mg}$. per cent, and cholesterol $189 \mathrm{mg}$. per cent. The total serum protein was $7.8 \mathrm{mg}$. per cent, with an albumin-globulin ratio of 1.2 .

X-ray examination (Fig. 1) revealed a $10 \mathrm{~cm}$. calcified thoracic aneurysm which had increased $1 \mathrm{~cm}$. in size since a chest film taken six months earlier. Electrocardiograms (Fig. 2) showed incomplete right bundle branch block, the $S_{1} Q_{3} T_{3}$ pattern, and symmetrical $T$-wave inversion in Leads II, III, $F$, and $V_{1-3}$. An intravenous angiogram was done with serial biplane filming. The right atrium was normal. The right ventricle was moderately enlarged. The pulmonic valve and the common pulmo-

From the Division of Cardiology (Heart Station), Department of Internal Medicine, The University of Michigan Medical Center, Ann Atbor, Mich.

This work was supported in part by United States Public Health Service-National Institutes of Health Grant 5 T02 HE 5114-15.

Received for publication June 11, 1970.

Reprint requests to: Dr. Park W. Willis, III, M.D., Heart Station, University Hospital, Ann Arbor, Mich. 48104. 
nary artery were normal. The left pulmonary artery did not visualize and the right pulmonary artery was compressed at its origin (Fig. 3). The caliber of the vessels on the right beyond the partial obstruction appeared increased. The pulmonary veins, left atrium, left ventricle, and ascending aorta appeared normal. There was a large saccular aortic aneurysm of the arch distal to the left subclavian artery which was almost completely filled with laminated clot. The remainder of the aorta was normal. A right heart catheterization was performed (Table I) and showed right ventricular and common pulmonary artery hypertension with a $60 \mathrm{~mm}$. $\mathrm{Hg}$ pressure gradient at the bifurcation of the common pulmonary artery. Cineangiocardiograms demonstrated slowing of the circulation through the right side of the heart. The common pulmonary artery appeared "kinked." The remainder of the study confirmed the findings of aortography.

On the seventeenth hospital day a left thoracotomy was performed. The aneurysm, measuring $10 \mathrm{~cm}$. at its greatest diameter and $4 \mathrm{~cm}$. at its base, was dissected free of the lung surface. An attempt was made to isolate the aorta above and below the aneurysm. However, these manipulations further compromised the already partially obstructed pulmonary outflow tract and resulted in a decrease in systemic arterial pressure. It became necessary to use cardiopulmonary bypass during which diffuse bleeding began. When clot was evacuated from the aneurysm, the left pulmonary artery began to pulsate vigorously. 'The aneurysm was excised from the anterolateral aspect of the aorta and replaced by a Teflon graft. However, despite all measures, the diffuse bleeding became more severe and the patient died in the operating room.

\section{Discussion}

The pulmonary artery arises from the infundibulum of the right ventricle behind the sternal end of the second left intercostal space. It is about $5 \mathrm{~cm}$. in length and $3 \mathrm{~cm}$. in diameter in the adult and is entirely enclosed within the fibrous pericardium. It passes upward and backward while curving through the mediastinum from a position in front of the ascending aorta to a position left of the aorta. Anywhere along this path a vascular, neoplastic, or inflammatory lesion can compromise the outflow tract, masquerade as pulmonic stenosis, and produce right ventricular failure.

The early clinical finding of acquired right ventricular outflow tract obstruction is a systolic ejection murmur accompanied by a thrill over the upper left sternal border. The murmur may be continuous (machinery-like) and resemble that of patent ductus arteriosus. Such a murmur in the presence of a thoracic aortic aneurysm is suggestive of acquired right ventricular

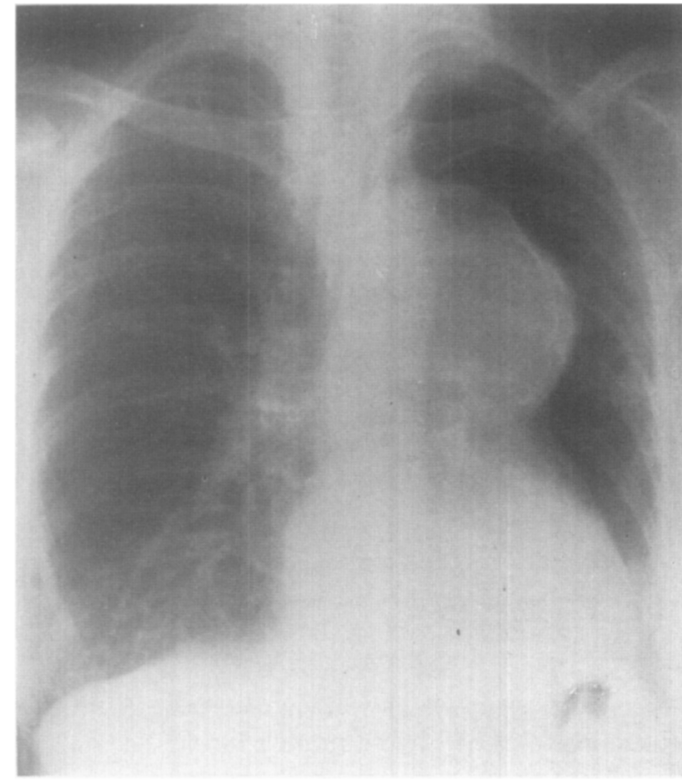

Fig. 1. Chest roentgenogram showing calcified thoracic aortic aneurysm.

Table I. Results of right heart catheterization

\begin{tabular}{l|l}
\hline Site & Pressure (mm. Hg) \\
\hline RA & $7 / 0$ (mean 4) \\
RV & $82 / 19$ \\
HRV & $75 / 5$ \\
RPA & $20 / 10$ \\
\hline
\end{tabular}

Peak systolic pressure gradient at bifurcation of pulmonary artery $-60 \mathrm{~mm}$. Hg.

$\mathrm{RA}=$ right atrium; $\mathrm{RV}=$ right ventricle; $\mathrm{HRV}=$ high right ventricle; RPA $=$ right pulmonary artery.

outflow tract obstruction. ${ }^{1,2}$ The electrocardiogram is helpful if it shows increasing right axis deviation and other signs compatible with right ventricular hypertrophy. Chest pain and dyspnea are common presenting symptoms. ${ }^{3}$

The most common lesion producing acquired right ventricular outflow tract obstruction is an aortic aneurysm, particularly a syphilitic aneurysm. ${ }^{4-14}$ The concave surface of the ascending aorta is a common site for the aneurysm which may enlarge anteriorly and to the left and deform the lumen of the pulmonary artery. In 1839, Hope $^{15}$ described a patient with an aortic aneurysm which ruptured into the pulmonary artery. Peacock ${ }^{16}$ in 1868 and Kap- 


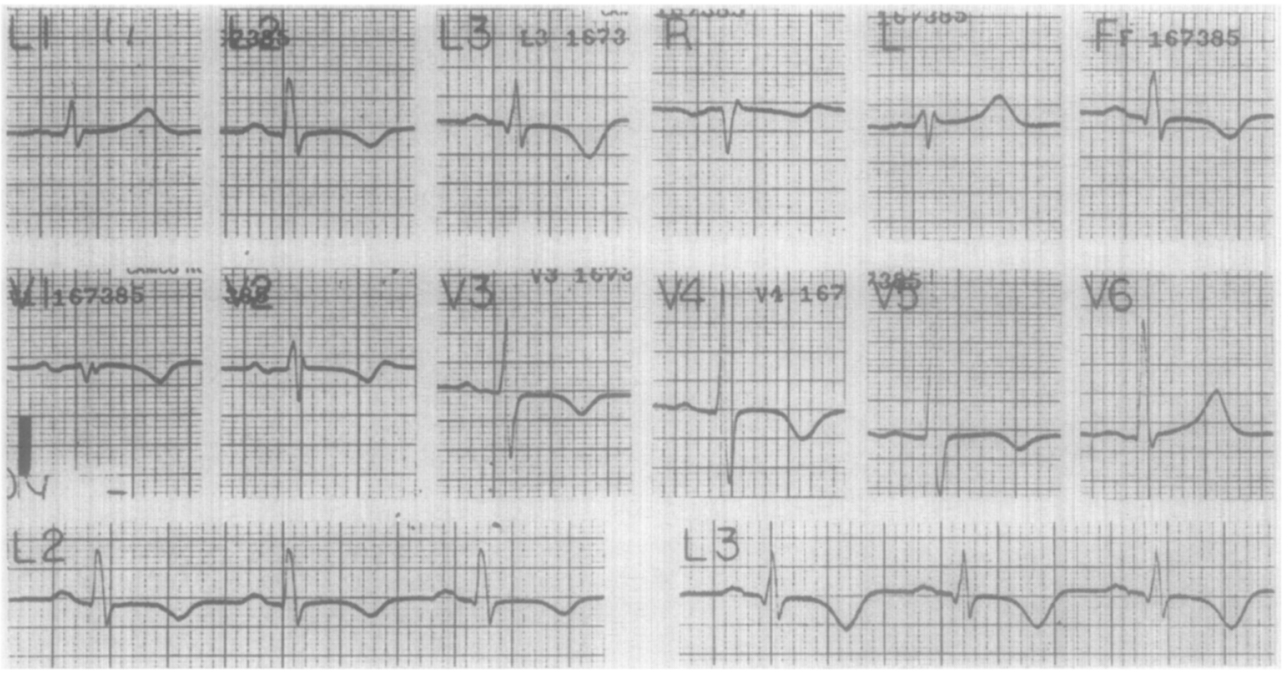

Fig. 2. Electrocardiogram demonstrating findings which may be the result of right ventricular hypertension (incomplete right bundle branch block, $\mathrm{S}_{1} \mathrm{Q}_{3} \mathrm{~T}_{3}$ pattern, and symmetrical $\mathrm{T}$-wave inversion in Leads II, III, $\mathrm{F}$, and $\mathrm{V}_{\mathrm{I}-\mathrm{s}}$ ).

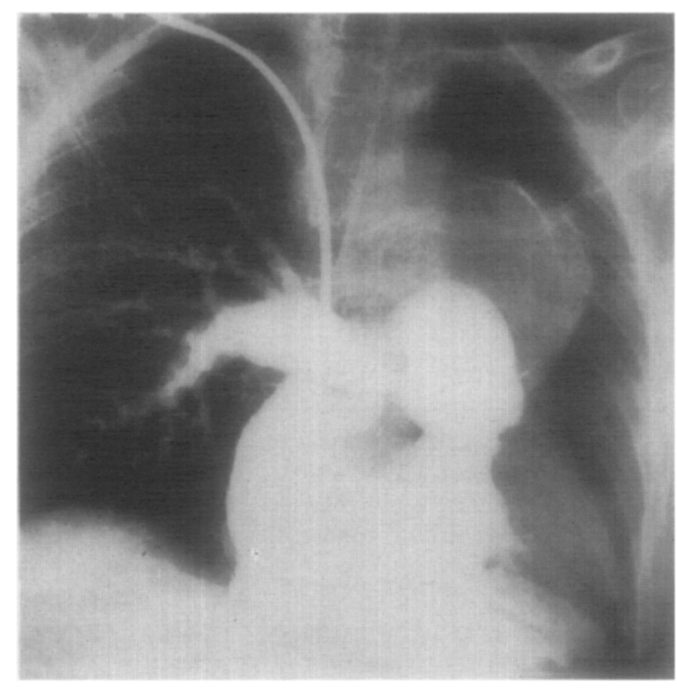

Fig. 3. Intravenous angiogram revealing a large saccular aortic aneurysm of the arch distal to the left subclavian artery totally obstructing the left pulmonary artery and compressing the origin of the right pulmonary artery.

pis $^{17}$ in 1907 each reviewed the literature and reported 19 and 32 similar cases, respectively. The signs and symptoms of the rupture of an aortic aneurysm into the right ventricular outflow tract were summarized by Porter $^{18}$ and Nicholson ${ }^{19}$ and each of these authors presented the clinical picture as a syndrome associated with syphilitic aortitis. Brill and Jones ${ }^{20}$ cited 87 patients of whom 84 (96.5 per cent) came to medical attention at the time of rupture of a syphilitic aneurysm into the pulmonary artery. Only 3 (3.5 per cent) of this group had symptoms due only to compression of the right ventricular outflow tract. A nonsyphilitic aortic aneurysm presenting in the latter fashion is an even rarer occurrence. Yacoub and associates ${ }^{21}$ presented one such case and another is reported in this paper.

Neoplasms rank second in frequency among the lesions producing right ventricular outflow tract obstruction. Primary intracardiac tumors which have been observed to compromise the right ventricular outflow tract included rhabdomyosarcoma, ${ }^{22-24} \mathrm{fi}$ brosarcoma, ${ }^{25}$ chondrosarcoma, ${ }^{26}$ reticulum cell sarcoma, ${ }^{27}$ myxoma, ${ }^{28,29}$ pleomorphic sarcoma, ${ }^{3}$ and mesothelioma of the pericardium. ${ }^{30}$ The only reported metastatic intracardiac lesion which has produced this type of obstruction is a malignant argentaffinoma. ${ }^{31}$ Extracardiac tumors which have mechanically obstructed the pulmonary artery include teratoma, ${ }^{3,32}$ Hodgkin's disease, ${ }^{3,33}$ thymoma, ${ }^{34,35}$ and bronchial carcinoma. $^{3}$

An annular constricting pericardial band is the most frequently encountered inflammatory lesion producing acquired obstruction. Gouley ${ }^{36}$ described five instances of rheumatic pericarditis which resulted in 
supravalvular pulmonic stenosis. Mounsey $^{37}$ and McGaff and associates ${ }^{38}$ have reported patients with subvalvular obstruction due to a pericardial band. Barros and Gomez $^{39}$ described a patient with a pericardial band constricting the right ventricular outflow tract and noted that a partial pericardiectomy had antedated the acquired obstruction in his patient and in those mentioned above. Seymour and coworkers ${ }^{3}$ discussed a similar patient with right ventricular outflow tract obstruction after incomplete pericardiectomy. Weglicki and colleagues ${ }^{40}$ reported one case of acquired pulmonic stenosis due to a pericardial band without previous pericarditis or pericardial surgery.

Chronic fibrous mediastinitis, ${ }^{41,42}$ miliary tuberculosis, ${ }^{43}$ and callus formation of the sternum $^{44}$ are other inflammatory lesions which have produced right ventricular outflow tract obstruction.

Although acquired right ventricular outflow tract obstruction is an unusual cause of right ventricular failure, it is not such a rare postmortem finding that the clinician should not keep the possibility high on the list of conditions to be considered when he is faced with the inexplicable and gradual onset of right ventricular failure-particularly when this is associated with a "new" ejection murmur along the upper left sternal border.

\section{REFERENCES}

1. Garvin, C. F., and Siegel, M. L.: Cor pulmonale due to obstruction of the pulmonary artery by syphilitic aortic aneurysms, Amer. J. Med. Sci. $198: 679,1939$.

2. Levin, H. S., and Booth, R. W.: Lymph node compression of the pulmonary artery causing a continuous murmur, Amer. J. Cardiol. 6:972, 1960.

3. Seymour, J., Emanuel, R., and Pattinson, N.: Acquired pulmonic stenosis, Brit. Heart J. 30:776, 1968.

4. Scott, R. W.: Aortic aneurysm rupturing into the pulmonary artery, J.A.M.A. 82:1417, 1924.

5. Crawford, J. H., and DeVeer, J. A.: Aneurysm of the aorta producing pulmonic stenosis and bundle branch block, AMER. HEART J. $7: 780$, 1932.

6. Delp, M. H., and Maxwell, R.: Rupture of an aortic aneurysm into the pulmonary artery, J.A.M.A. 110:1647, 1938.

7. Dickens, K. L.: Pulmonary stenosis produced by aneurysm of the ascending aorta, Brit. Heart J. 2:247, 1940.
8. White, P. D., Chamberlain, F. L., and Kelson, S. R.: Rupture of aorta into the pulmonary artery with long survival, Ann. Intern. Med. 15:589, 1941.

9. Schattenberg, H. J., and Harris, W. H.: Aortic aneurysm with rupture into the pulmonary artery, Amer. IIEART J. 25:512, 1943.

10. Eichler, B. B., and Heller, S. N.: Aneurysm of aorta with compression of pulmonary artery and left auricle, Ann. Intern. Med. 23:653, 1944.

11. Pearson, J. R., and Nichol, E. S.: The syndrome of compression of the pulmonary artery by a syphilitic aortic aneurysin resulting in chronic cor pulmonale, with report of a case, Ann. Intern. Med. 34:483, 1951.

12. Donnell, J. L., Levinson, D. C., and Griffith, G. C.: Clinical studies on involvement of the pulmonary artery by syphilitic aortic aneurysms, Circulation 13:75, 1956.

13. Schrire, V., Beck, W., and Barnard, C. N.: Aneurysm of the ascending aorta obstructing right ventricular outflow and producing severe "pulmonary stenosis," AmEr. Heart J. 15:396, 1963.

14. Bevin, A. G., Rojas, R. H., and Stansel, H. C., Jr.: Aneurysm of the aorta causing obstruction of the left pulmonary artery, J. Thorac. Cardiovas. Surg. 52:245, 1966.

15. Hope, J.: Treatise on the diseases of the heart and great vessels, Philadelphia, 1842, Haswell \& Johnson, pp. 439-442.

16. Peacock, T. B.: Aneurysm of the ascending aorta pressing upon the base of the right ventricle and opening in the origin of the pulmonary artery; with remarks on the communications of the sacs of aneurysms with the cardiac cavities and adjacent vessels, Trans. Path. Soc. London 19:111, 1867-1868.

17. Kappis, M.: Die Perforation eines Aortenaneurysma in die Pulmonalarterie, Deutsch. Arch. f. Klin. Med. 90:505, 1907.

18. Porter, W. B.: The syndrome of rupture of an aortic aneurysm into the pulmonary artery, Amer. Heart J. 23:468, 1942.

19. Nicholson, R. E.: Syndrome of rupture of aortic aneurysm into the pulmonary artery: Review of the literature with report of two cases, Ann. Intern. Med. 19:286, 1943 .

20. Brill, I. C., and Jones, R. S.: The syndrome of compression of the pulmonary artery by a syphilitic aortic aneurysm with or without arterio-arterial communication, Ann. Intern. Med. 24:111, 1946.

21. Yacoub, M. H., Braimbridge, M. V., and Gold, R. G.: Aneurysm of the ascending aorta presenting with pulmonic stenosis, Thorax 21:236, 1966.

22. Mannix, E. P., Jr., and Lukash, L.: Primary rhabdomyosarcoma of the heart producing marked obstruction of the pulmonary valve, St. Francis Hosp. Bull. 15:14, 1958.

23. Hallerman, F. J., Kincaid, O. W., Brown, A. L. and Daugherty, G. W.: Rhabdomyosarcoma of the heart producing right ventricular outflow tract obstruction, J.A.M.A. 184:939, 1963.

24. Pund, E. E., Collier, T. M., and Cunningham, 
J. E.: Primary cardiac rhabdomyosarcona presenting as pulmonic stenosis, Amer. J. Cardiol. 12:249, 1963.

25. Goldstein, S., and Mahoney, E.: Right ventricular fibrosarcoma causing pulmonic stenosis, Amer. J. Cardiol. 17:570, 1966.

26. Del Castillo, J. J., Gianfrancesco, H., and Mannix, E. P., Jr.: Pulmonic stenosis due to compression by sternal chondrosarcoma, J. Thorac. Cardiovasc. Surg. 52:255, 1966.

27. Folkins, D. F., Anderson, R. N., and Cooper, J. H.: Case report: Pulmonary outflow tract obstruction produced by primary reticulum cell sarcoma, Canad. Med. Ass. J. 93:1319, 1965.

28. Gottsegen, G., Wessely, J., Arvay, A., and Temesvari, A.: Right ventricular myxoma simulating pulmonic stenosis, Circulation 27:95, 1963.

29. Catton, R. W., Guntheroth, W. G., and Reichenbach, D. O.: A myxoma of the pulmonary valve causing severe pulmonic stenosis in infancy, Amer. Heart J. 66:248, 1963.

30. Waldhausen, J. A., Lombardo, C. R., and Morrow, A. G.: Pulmonic stenosis due to compression of the pulmonary artery by an intrapericardial tumor, J. Thorac. Sury. 37:679, 1959.

31. Jenkins, J. S., and Butcher, P. J. A.: Malignant argentaffinoma with cyanosis and pulmonary stenosis, Lancet $1: 331,1955$

32. Fry, W., Klein, C. L., and Barton, Y. C.: Malignant mediastinal teratoma simulating cardiovascular disease, Dis. Chest $27: 537,1955$.

33. Babcock, K. B., Judge, R. D., and Bookstein, J. J.: Acquired pulmonic stenosis, Circulation 26:931, 1962.

34. Winter, B.: Pulmonic stenosis produced by compression of heart by anterior mediastinal tumor, AMER. HeArT J. 55:18, 1958.
35. Shaver, V., Bailey, W. R., and Marrangoni, A. G.: Acquired pulmonic stenosis due to external cardiac compression, Amer. J. Cardiol. $16: 256,1965$.

36. Gouley, B. A.: Constriction of pulmonary artery by adhesive pericarditis, Amer. Heart J. $13: 470,1937$.

37. Mounsey, P.: Annular constrictive pericarditis with an account of a patient with functional pulmonary, mitral, and aortic stenosis, Brit. Heart J. $21: 325,1959$.

38. McGaff, C. J., Haller, J. A., Leight, I.., and Towery, B. T.: Subvalvular pulmonic stenosis due to constriction of right ventricular outflow tract by a pericardial band, Amer. J. Med. 34:142, 1963.

39. Barros, J. C., and Gomez, F. P.: Pulmonic stenosis due to external compression by a pericardial band, Brit. Heart J. $29: 947,1967$.

40. Weglicki, W. B., Lee, J. F., Brown, J. W., and Whalen, R. E.: Infundibular pulmonic stenosis due to pericardial band, Amer. J. Cardiol. 16:262, 1965 .

41. Nelson, W. P., Lundberg, G. D., and Dickerson, R. B.: Pulmonary artery obstruction and cor pulmonale due to chronic fibrous mediastinitis, Amer. J. Med. 38:279, 1965.

42. DuPont, H. L., Varco, R. L., and Winchell, C. P.: Chronic fibrous mediastinitis simulating pulmonic stenosis, associated with inflammatory pseudotumor of the orbit, Amer. J. Med. 44:447, 1968.

43. Gilmore, H. R.: Tuberculosis involving the pulmonary valve, Amer. J. Path. 16:229, 1940.

44. Rubicsek, F., Bustuen, H., Daugherty, H. K., and Sanger, P. W.: Severe extrinsic pulmonic stenosis due to callus formation of the sternum, Ann. Thorac. Surg. 4:440, 1967. 